American Journal of Pharmaceutical Education 2009; 73 (8) Article 137.

\title{
VIEWPOINTS
}

\section{Why Do We Still Lecture?}

\author{
Joseph T. DiPiro, PharmD \\ Editor, American Journal of Pharmaceutical Education
}

Many of us have had the experience of asking a thirdor fourth-year pharmacy student about a lecture from their first year, to learn not only did they not recall the topic or the lecturer, they only had a vague recollection of the entire course. Students often describe "cramming" of factual information in the days before an examination; however, this results in only modest long-term retention. These experiences highlight a fault of our time-honored tradition of teaching by passive lecture. Passive lectures provide the lowest knowledge retention rate of any method of learning and encourage learning at the lowest levels of cognitive function. In contrast, active learning that involves discussion, practicing by doing, or teaching others, results in much more effective long-term learning at higher levels of cognitive function, and is more likely to produce desired attributes in pharmacists.

The time-honored method of "presenting" factual material to a class of passive learners is still considered good teaching. We may even judge a passive lecture that is well organized, clear, relevant, and up-to-date as being high quality. But it clearly does not maximize learning efficiency or account for differences in learning styles. Some of the concerns with traditional approaches to teaching were well expressed in this Journal by Blouin and colleagues ${ }^{1}$ and expanded on in this issue. ${ }^{2}$

The passive lecture and Powerpoint bullet-slide approach to teaching would be acceptable if the knowledge required to practice were static, and if memorization were the key to successful practice as a pharmacist. Clearly they are not. There is little relevant information remaining from my pharmacy degree program completed 30 years ago. In fact, one could argue that enough factual material changes over 4 years, that graduating students should start again to learn an up-to-date version of much of what was presented during their first year. The factual information that we spend so much time conveying to students is rapidly outdated, and it is the critical thinking, problem solving, communication, and life-long learning skills that best prepare students for the decades of practice after graduation.

Lecturing assumes a "one-size fits all" approach to learning. Traditional lectures beg the question, why do students who have advanced knowledge need to sit

through required lectures that add nothing to their knowledge base? The lecture material that may be understood by one student may be particularly challenging for another. The passive lecture provides limited opportunity for the less advanced student to learn foundational concepts.

Journal authors have provided many examples of learning approaches that break the traditional lecture mold. Experiential education in most forms is the best example, along with classroom approaches that include discussion, "1-minute" papers, think-pair-share activities, learning by teaching, games, and in-class formative assessments of learning. Richard J. Light of Harvard University described a research-based approach to demonstrate "Making the Most of College." He found that engaging with faculty members and fellow students, working in groups, participating in courses that require writing, and being involved in extracurricular activities had the most influence on students' success in college and were the activities and information best remembered after graduation. $^{3}$

The paper by Blouin and colleagues presents a path for curricular innovation. It calls for a reexamination of what happens in our classrooms and calls for rejection of the use of classroom time for the simple transmission of factual information. We should actively work toward and welcome the demise of traditional passive lectures. Teaching of factual information will always be necessary but should make the best use of state-of-the-art technology to provide more flexibility in the time and place and pace of learning. Knowledge delivery should be an anytime, anywhere process. More efficient delivery of factual information outside of the classroom will allow more time to be devoted to active learning in its many forms.

\section{References}

1. Blouin RA, Joyner PU, Pollack GM. Preparing for a renaissance in pharmacy education: the need, opportunity, and capacity for change. Am J Pharm Educ. 2008;72(2):Article 42.

2. Blouin RA, Riffee WH, Robinson ET, et al. Roles of innovation in education delivery. Am J Pharm Educ. 2009;73(8):Article 154.

3. Light RJ. Making the Most of College: Students Speak Their Minds. Cambridge, MA: Harvard University Press; 1991. 